\title{
ADOLESCENTES NA ERA DIGITAL: OFICINAS DE ENSINO DE LÍNGUA ESPANHOLA PARA A INCLUSÃO SÓCIO LABORAL USANDO O MOODLE
}

\author{
Patricia C. Incola ${ }^{1}$, Adriana C. Barbosa ${ }^{2}$, Sissy V. Fontes ${ }^{3}$ \\ ${ }^{1}$ Instituto Federal de Ciência e Tecnologia de Espírito Santo (Ifes) \\ Rodovia ES-010, Km 6.5, Manguinhos - 29173-087 - Serra - ES - Brasil \\ ${ }^{2}$ Instituto Federal de Ciência e Tecnologia de Espírito Santo (Ifes) \\ Rodovia ES-010, Km 6.5, Manguinhos - 29173-087 - Serra - ES - Brasil \\ ${ }^{3}$ Departamento de Neurologia e Neurocirurgia - Universidade Federal de São Paulo \\ (UNIFESP) \\ R. Estado de Israel, 899 - 04022-002 - Vila Clementino - São Paulo - SP - Brasil \\ patriciacecilia.i@gmail.com, adrianadacostabarbosa@gmail.com, \\ sissyfontes@gmail. com
}

\begin{abstract}
This paper describes the integration of Web 2.0 in foreign language classes, specifically Spanish (LE/E), where the use of information and communication technologies (ICTS) can surpass the space-time conditions of the traditional education system. According to UNICEF (2013), 3.7 million children and teenagers in Brazil do not go to school due to lack of motivation or low grades. Therefore, we propose the Integrative Educational Project for the Born in the Digital Age for teaching Spanish by means of ICTs, aiming at improve the selfesteem of the students and encourage them to make the most of the opportunities given in life. A future pilot will tabulate data so that we can elaborate how a specific group of students experience a technological innovation trend in time.
\end{abstract}

Keywords: Teenagers. Spanish language. Moodle. ICTs. Integrative Care.

Resumo. Este artigo comenta a integração da Web 2.0 nas aulas de língua estrangeira, especificamente o espanhol (LE/E) onde o uso das TICs pode superar os condicionamentos espaciotemporais do sistema educativo tradicional. Segundo a UNICEF no Brasil (2013) 3,7 milhões de crianças e adolescentes estão fora da escola devido a fatores como falta de motivação e baixo desempenho escolar. Pensando nesses jovens propõe-se o "Projeto Educacional Integrativo para os Nascidos na Era Digital (PEINED)" de cunho educativo de língua espanhola, mediado pelas TICs, visando fomentar a autoestima e a valorização da vida. Um futuro piloto tabulará dados e refletiremos de que maneira um determinado grupo de estudantes vivencia um momento de inovação tecnológica.

Palavras-chave: Adolescentes. Idioma espanhol. Moodle. TICs. Cuidados Integrativos.

\section{Introdução}

No ensino de uma língua estrangeira, especificamente o espanhol (LE/E) a integração da Web 2.0 nas aulas pode superar os condicionamentos espaço temporais do sistema 


\section{CBIE-LACLO 2015}

Anais dos Workshops do IV Congresso Brasileiro de Informática na Educação (CBIE 2015)

educativo tradicional baseado nas aulas presenciais. Os últimos dez anos foram extraordinariamente fecundos em avanços tecnológicos aplicáveis à educação, no entanto, dados divulgados pela UNICEF no Brasil em 2013 constatam que 3,7 milhões de crianças e adolescentes estão fora da escola, devido entre outros, a fatores como falta de motivação e baixo desempenho escolar. Pensando nos jovens brasileiros que sofrem com a desvantagem socioeconômica e estão cada vez mais espremidos entre um sistema de educação pública que os marginaliza e à necessidade de ganhar dinheiro em um mercado de trabalho precário, este trabalho propõe um projeto denominado Projeto Educacional Integrativo para os Nascidos na Era Digital (PEINED) de cunho educativo de língua espanhola mediado pelas TICs para fomentar a autoestima e a valorização da vida, com vistas à promoção do bem social. Visando analisar e propor soluções que reintegrem adolescentes, atualmente fora do ambiente escolar, este trabalho tece uma rede interrelacionando TICs, aprendizagem significativa do idioma espanhol, metodologia comunicativa e com uma abordagem epistemológica de Cuidados Integrativos, na interface com a educação do "Bem Ser".

\section{Enfoque Comunicativo e Cuidados Integrativos}

O chamado enfoque comunicativo tem influenciado o ensino de idiomas desde o inicio da década 1970. Segundo Littlewood (1998, p. 1) o enfoque comunicativo não só considera a língua em função de suas estruturas gramaticais e léxicas, mas também, a partir das funções comunicativas que a mesma cumpre. Por exemplo, a forma: "¿Por qué no cierras esa puerta?” poderia ter várias funções comunicativas, tais como fazer uma pergunta, sugerir ou dar uma ordem. Isso nos leva a pensar que não é suficiente ensinar a manipular as estruturas da língua estrangeira, também é preciso desenvolver estratégias para relacionar essas estruturas com suas funções comunicativas em situações e tempos reais. O enfoque comunicativo aplicado ao ensino do idioma espanhol dá amplo significado às atividades pedagógicas virtuais do projeto PEINED.

“Cuidados Integrativos consiste em um 'novo paradigma' que associa conhecimentos orientais e gregos arcaicos, sabedoria de povos nativos e avanços tecnocientíficos ocidentais modernos promovendo a interface entre, além e através dos eixos Saúde e Educação. Fontes (2014) lembra que é uma prática de saúde e educação alicerçada em valores universais, éticos e morais com método, teorias, técnicas, e habilidades próprias. "Essa indissolubilidade entre a saúde, como uma visão sistêmica e a educação, alicerçada na visão transdisciplinar, cujo modelo de ensino admite, a partir do lugar do terceiro incluído, os diferentes níveis de realidade e a complexidade, o que propicia nova tomada de consciência do saber, do sentir e do fazer, com base no Ser que cuida de Si, do Outro e do Planeta." (FONTES 2014).

Para o educador que se depara com o desafio de lidar com jovens em situação de risco, na abordagem dos Cuidados Integrativos a escolha da metodologia se reveste de um significado especial, e esse percurso de educação/saúde tem como referencial o paradigma "Salutogênico", que prima o foco na habilidade, e não na deficiência.

Segundo a UNICEF no Brasil (2013), dos 3,7 milhões de crianças e adolescentes divulgados pela Pnad em 2009, mais de 1,5 milhão de adolescentes entre 15 e 17 anos permanecem fora da escola. Seguido de 1,4 milhão de crianças entre 4 e 5 anos; 375 mil crianças entre 6 a 10 anos e 355 mil crianças entre 11 a 14 anos. Em virtude desse cenário propomos um programa educacional apoiado nas TICs, com uma visão 
integrativa alicerçada nos três pilares pedagógicos dos Cuidados Integrativos, que são o autoconhecimento (sujeito com ele mesmo), a alteridade (sujeito com o outro) e a transdisciplinaridade (sujeito com o todo) (Fontes 2014) e que pode ser um facilitador no "diálogo" entre educadores e os educandos que o sistema educacional público não conseguiu reter.

\section{Moodle como ferramenta no ensino-aprendizagem de língua estrangeira}

PEINED é um projeto em desenvolvimento desenhado para dar suporte num marco de educação social construtivista. A metodologia está dividida em dois campos: virtual e presencial. O virtual corresponde a $80 \%$ das aulas e será implementado com o auxílio da plataforma Moodle, acrónimo de Modular Object-Oriented Dynamic Learning Environment e de sala de videoconferência. As atividades no Moodle são centradas nos estudantes e realizadas de forma autônoma e interativa permitindo aos participantes construir o conhecimento de forma cooperativa. Além disso, as atividades são propostas de forma que o estudante ficará responsável pela busca da informação necessária para cumprir a tarefa, com essa finalidade, a comunicação poderá dar-se com seu interlocutor através do chat, wiki, fórum etc. As atividades de comunicação oral, importantíssimas para o estudo de língua estrangeira, são realizadas através de videoconferência, com a mediação do professor.

A figura 1 apresenta a tela de login da área do aluno. Ao acessar o ambiente o participante é recebido com uma mensagem onde ele é o protagonista.

A página inicial da Área do Aluno está ilustrada pela figura 2. É possível verificar que no centro, tem-se o espaço Novidades, reservado para a publicação de informações relevantes para o aluno, como por exemplo: datas de eventos, notícias etc. Na parte esquerda, está o menu Navegação com as opções de: Minha página inicial para visualizar os cursos em que o aluno está cadastrado; Páginas do site contendo os links disponíveis em relação ao Moodle; Meu perfil para visualizar e edita-lo e Meus cursos para acessar as atividades e exercícios dos cursos em que o participante está cadastrado. Ao escolher a opção Meus cursos o aluno visualizará as pastas dos cursos em que está cadastrado e poderá participar das atividades, dos fóruns, enviar e receber arquivos, emails e acompanhar o calendário de eventos dentre outras opções. A figura 3 ilustra a seção Cursos que contem ilustrativamente os cursos: Cursos regulares, Mundo del Trabajo, Cajón de Sastre, Ambiente Cooperativo e Diagnóstico de Nivel. Cumpre destacar que o curso regular está dividido nos seguintes níveis: A1; A2; B1; B2; C1. Cada nível está integrado por unidades que representam um campo semântico do idioma. Ao selecionar o nível cursado, a página de início apresenta os descritores das destrezas e habilidades a desenvolver, e os campos semânticos a serem trabalhados conforme o nível escolhido. Ainda, se descreve o curso enquanto a sua carga horária, quantidade de horas de aula com o professor online, quantidade de horas requeridas para o trabalho individual na plataforma etc. 
CBIE-LACLO 2015

Anais dos Workshops do IV Congresso Brasileiro de Informática na Educação (CBIE 2015)

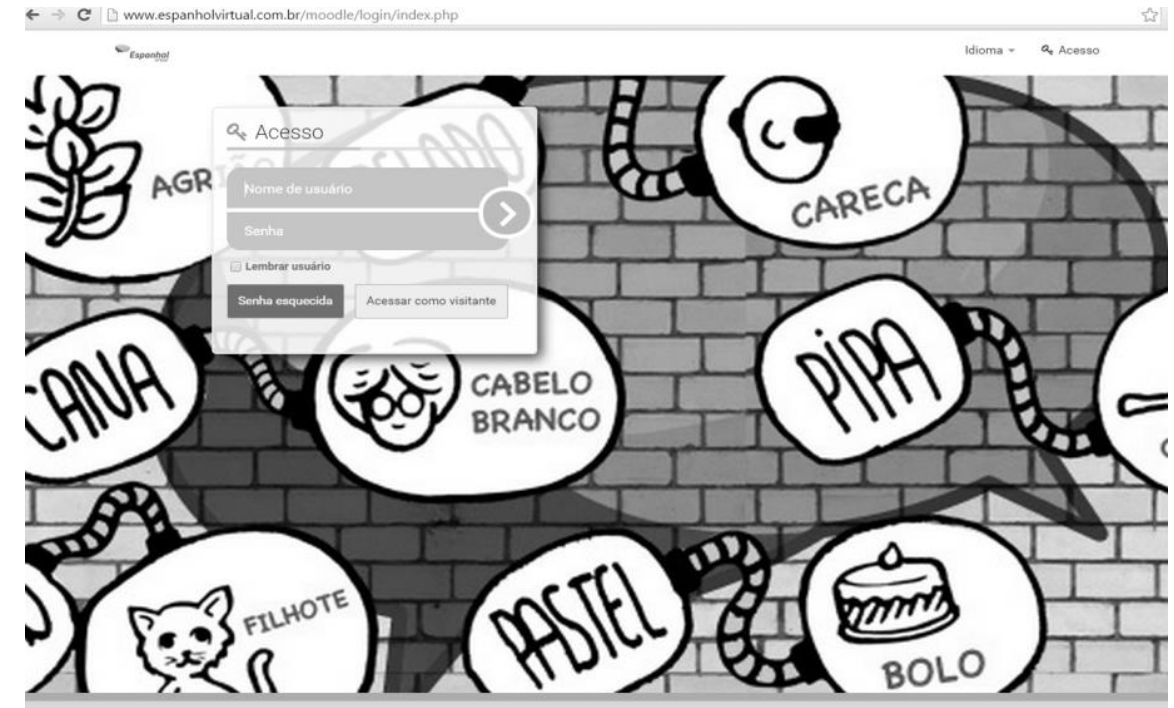

Figura 1. Tela de login

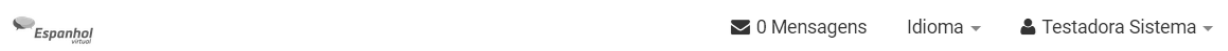

Los Diplomas DELE están reconocidos a nivel internacional, y gozan de un gran prestigio, no solo entre instituciones y autoridades educativas públicas y privadas sino también en el mundo empresarial y entre cámaras de comercio.

Convocatoria de abril 2015

- Día 17, niveles: A1, A2, B1, B2 y C1

- Inscripciones hasta el 11 de marzo

Convocatoria de mayo

- Día 22, niveles escolares: A1, A2/B1 (nuevo)

- Día 23, niveles: A1, A2, B1, B2, C1 y C2

- Inscripciones hasta el 8 de abril

\$ Administração E

Figura 2. Página inicial da Área do Aluno 


\section{CBIE-LACLO 2015}

Anais dos Workshops do IV Congresso Brasileiro de Informática na Educação (CBIE 2015)

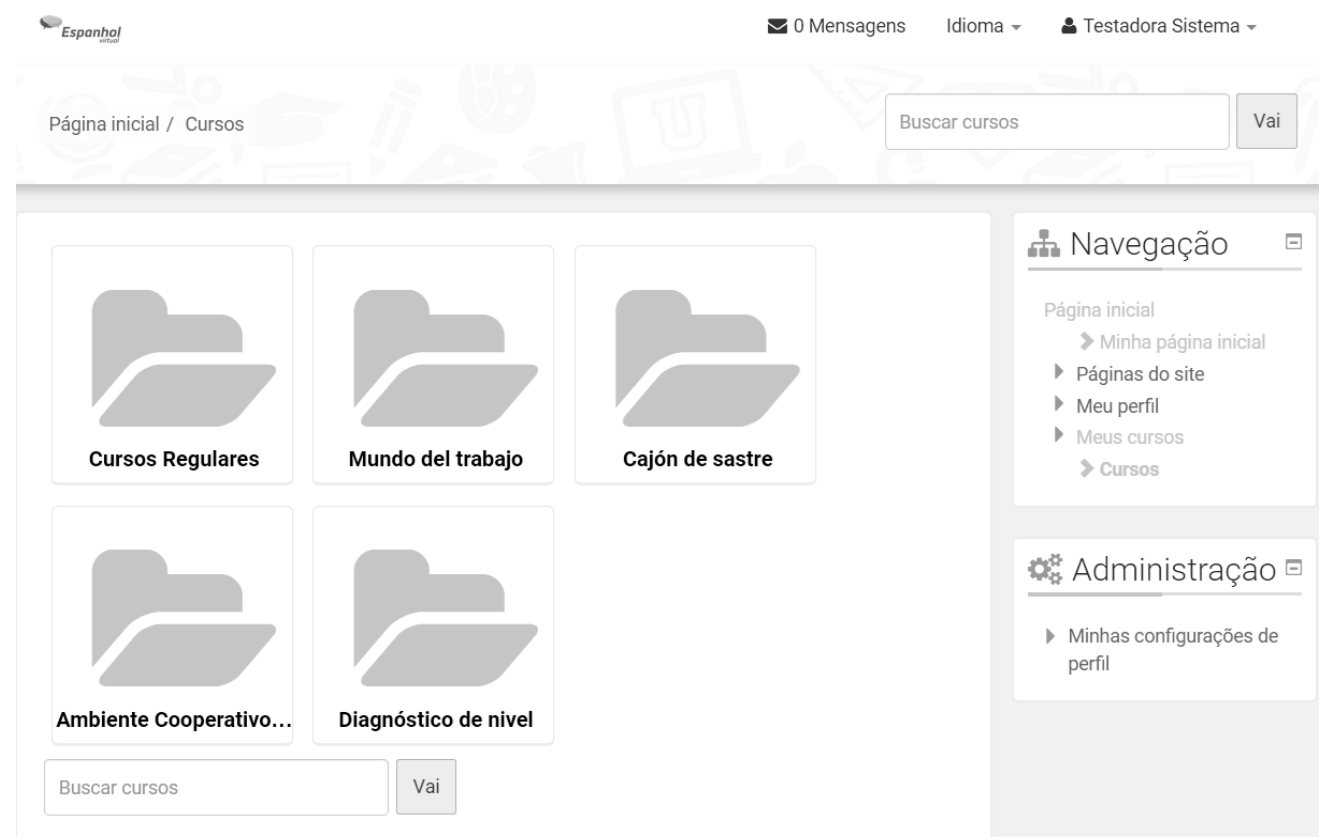

Figura 3. Tela Cursos

Os níveis estão organizados em unidades didáticas, que por sua vez estão divididas em tópicos numerados para trabalhar todas as destrezas comunicativas que são a audição, a comunicação oral e escrita e a compreensão leitora. Há diversas atividades com mídias distintas: podcasts, mp3 e vídeos para proporcionar a compreensão da língua estrangeira. Dentre todos os recursos, o vídeo é o instrumento por excelência, pois os falantes nativos podem ser vistos em situações autênticas e em contextos significativos.

O Moodle fornece várias ferramentas para a elaboração de exercícios, como por exemplo: questionário, resposta curta, envio de arquivo etc. No entanto, sem uma base metodológica para seu uso essas ferramentas, por si mesmas, não teriam aplicação no ensino de idiomas. Nesse contexto, ao desenvolver as unidades didáticas foram aplicados os conceitos do enfoque comunicativo através de atividades que facilitam a autonomia e a responsabilidade do estudante. Nas atividades foram selecionados conteúdos comunicativos que o aluno necessitará empregar como usuário da língua em situações reais, como por exemplo: se apresentar a outra pessoa ou cumprimentar e despedir-se, ilustrados na Figura 4; a isso chamamos de conteúdo funcional. O conteúdo linguístico corresponde à gramática necessária que é integrada de forma natural nas atividades. Com isso, transmite-se a ideia de aprendizagem como um processo, onde a língua espanhola é um elemento de interação, e assim, o aprendiz deve centrar-se na proficiência comunicativa dos elementos linguísticos tanto de uso social como cultural.

Para propiciar o contato do aluno com os diferentes registros da língua, $a \mathrm{Web}$ 2.0 oferece aos professores de idiomas inúmeros recursos com materiais autênticos, entre eles, os vídeos que podem ser facilmente integrados no Moodle. Assim, o educando é colocado em contato com a cultura, os costumes e a língua como os nativos usam, promovendo sua adaptação através da compreensão do conhecimento por meio da integração das destrezas. As histórias e as imagens dão uma visão de conjunto do conteúdo que foi trabalhado e da utilidade dessa informação. Os exercícios desenvolvidos a partir dos vídeos mantêm uma estrita relação e coesão com os conteúdos didáticos e buscam aperfeiçoar a capacidade crítica, imaginativa e criativa, 
além de aperfeiçoar a expressão oral e escrita e desenvolver a audição para os diferentes sotaques do idioma. A Figura 5 ilustra a integração do ambiente com atividades de vídeo.

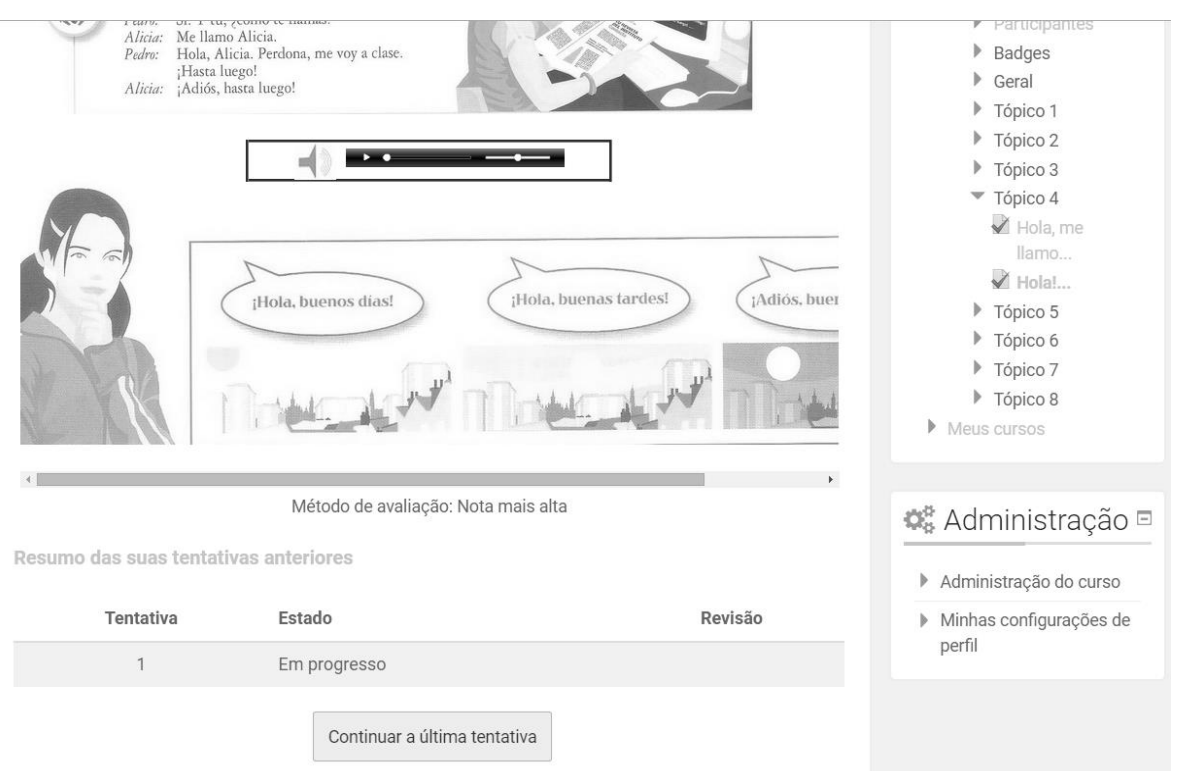

Figura 4. Atividade com enfoque comunicativo denominada ;Hola!

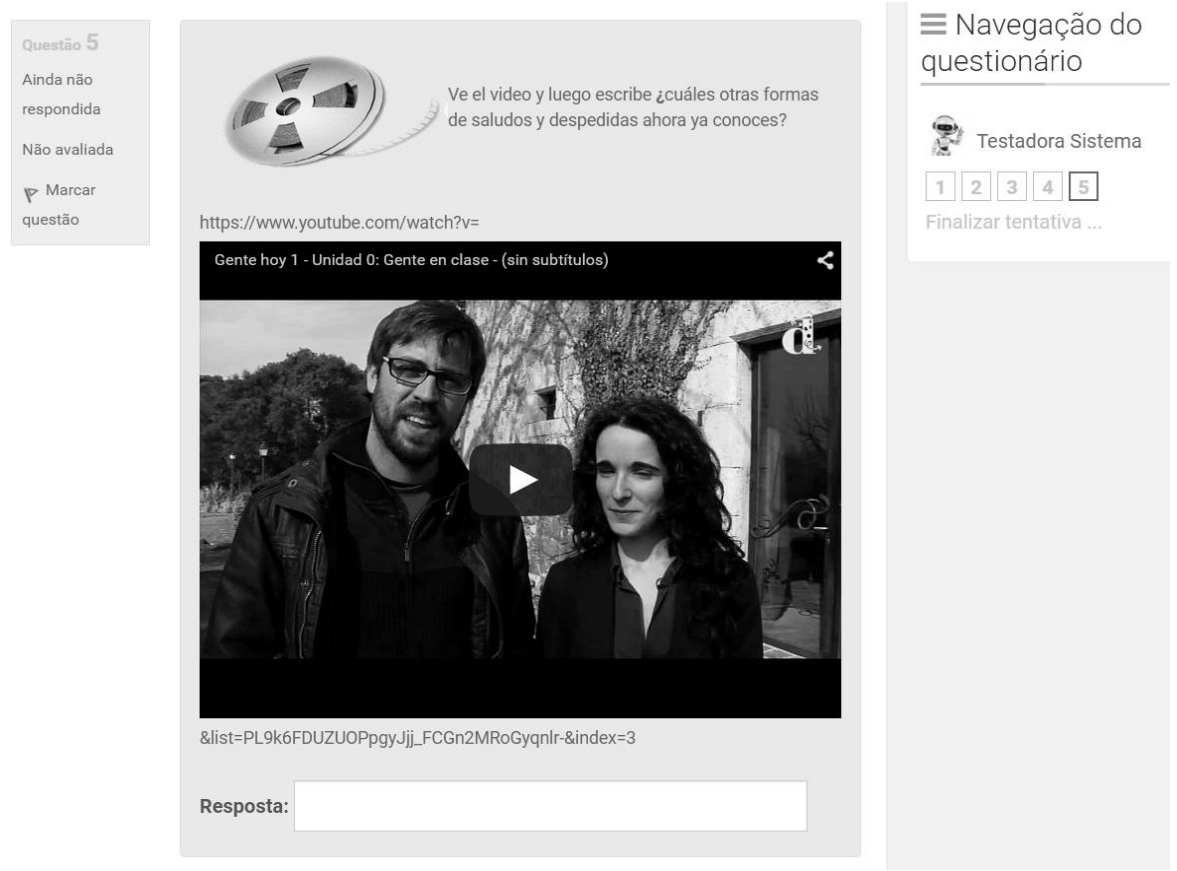

Figura 5. Atividade com integração de vídeo

\section{O Wiziq e o Moodle integrados ao ensino de idioma espanhol}

No Moodle a relação entre alunos e professores acontece pela troca de conhecimentos e de reflexão através da tecnologia. Para Primo (2007) o aluno é um sujeito ativo e reflexivo, que aprende a ter domínio do conhecimento a partir de sua autonomia. Portanto, o aluno tem que ser incentivado a ser um sujeito que pesquisa, que questiona, 


\section{CBIE-LACLO 2015}

Anais dos Workshops do IV Congresso Brasileiro de Informática na Educação (CBIE 2015)

gera "desequilíbrio" e contribui com suas próprias pontuações. A interação deve ser motivadora, e no ensino de línguas na modalidade à distância, aliado aos programas de videoconferência onde alunos e professores podem interagir de forma síncrona passa a ser fundamental.

No projeto PEINED as aulas de espanhol com o professor acontecerão através do programa de videoconferência Wiziq que é uma plataforma Web 2.0 com ferramentas simples e amigáveis. A sala de aula virtual promove o ensino à distância de forma síncrona permitindo o contato visual em tempo real, como é feito em uma sala de aula física. O professor elabora suas aulas ao vivo fazendo uso de vários recursos como quadro branco, vídeo, arquivos mp3, sala de bate-papo, ferramentas de votação e funções de gravação. Além da projeção do material didático produzido em arquivos Pdf e PowerPoint. É importante salientar que o professor deve estar familiarizado com a tecnologia para que ocorra uma aula significativa. A figura 6 ilustra o uso do Wiziq na unidade Estudiar en Barcelona.

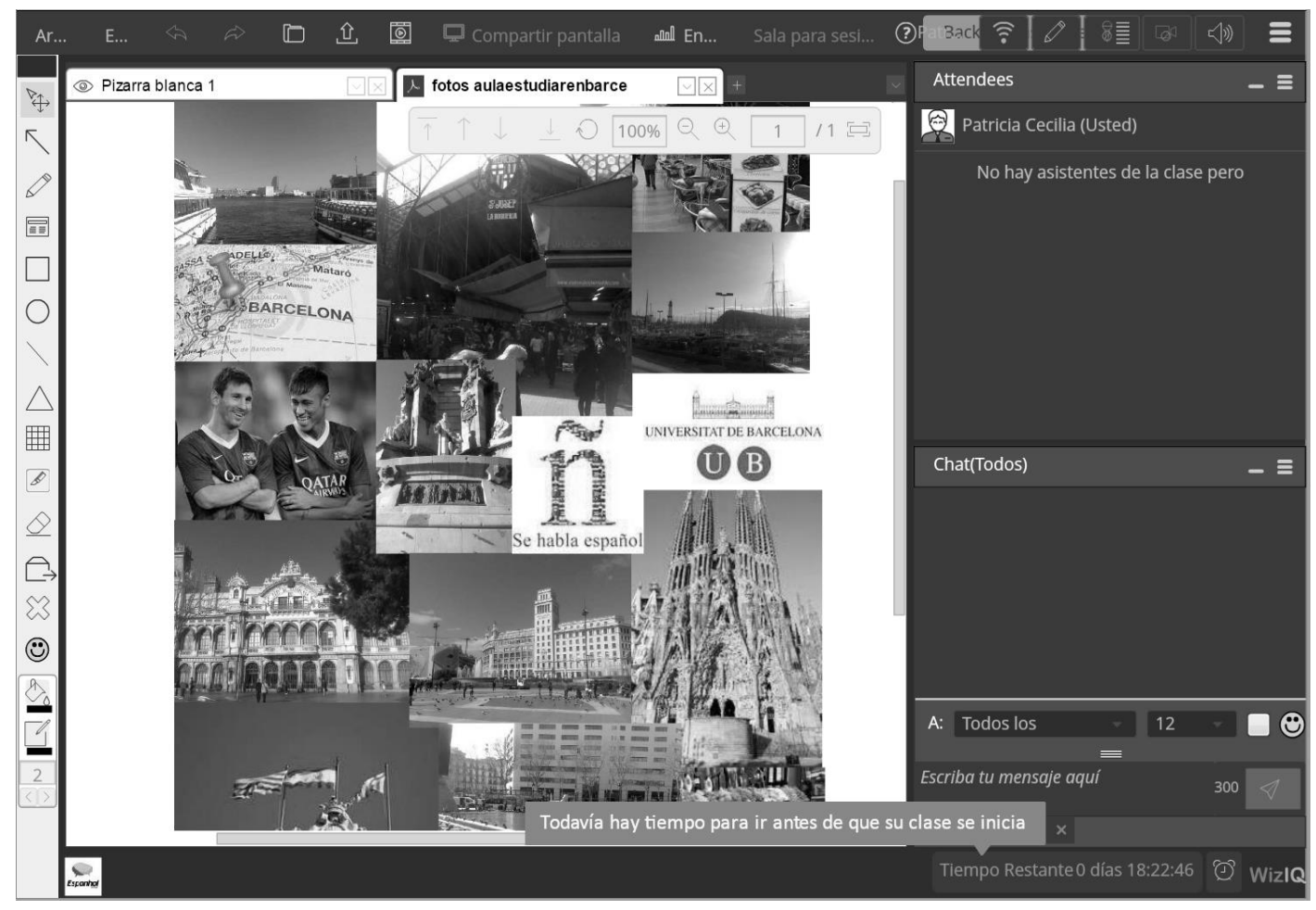

Figura 6. Atividade no Wiziq - Estudiar en Barcelona

\section{O presencial no PEINED}

Os jovens sujeitos deste estudo trazem para a sala de aula diversas experiências provenientes de anos escolares que derivaram na evasão e abandono escolar, muitas vezes, carregadas de conflitos e vivências advindos do convívio social e da família que podem causar bloqueios na aquisição de novo conhecimento. Assim, o projeto PEINED também é constituído por aulas presenciais que baseiam-se nos valores que norteiam a prática dos Cuidados Integrativos que são o autoconhecimento, a aprendizagem contínua, a cidadania, a ética, a alteridade, a transdisciplinaridade, a espiritualidade e o respeito a todas as formas de vida. 


\section{CBIE-LACLO 2015}

Anais dos Workshops do IV Congresso Brasileiro de Informática na Educação (CBIE 2015)

As aulas presenciais deverão acontecer aos finais de semana devido aos compromissos de trabalho e/ou familiares dos alunos no decorrer da semana e utilizarão como estratégia de ensino oficinas com diálogos e dinâmicas em grupo por meio de vivências, círculos de debates, exposições e aulas expositivas dialogadas elaboradas de maneira interdisciplinar. Littlewood (1998, p. 44-46) lembra com muita propriedade que as aulas de conversação ou debate, devido à variedade de experiências, opiniões e interesses dos estudantes, propiciam um forte estímulo para a interação comunicativa.

Procura-se através das atividades no idioma espanhol ajudar os jovens a entender as circunstâncias à sua volta e enfrentar os problemas. Com essa finalidade, a exposição da experiência do estudante nas aulas pode ser convertida pelo professor em um diálogo e até em situações simuladas na língua. Dessa forma, as atividades comunicativas no idioma espanhol são estimuladas pelo contexto, proporcionando a aprendizagem. Além disso, o debate é usado como meio importante para explorar a vivência dos jovens.

Corroborando com Littlewood (1998, p. 43) a língua estrangeira também pode ser utilizada nas atividades fora da aula de idioma. O enfoque comunicativo supõe aprender também nas diversas atividades criando oportunidades significativas e com boa motivação. Por isso, é importante proporcionar a língua necessária para questões rotineiras da sala, a fim de fixar, em nosso caso, o idioma espanhol como meio para organizar atividades de aprendizagem.

\section{Avaliação no PEINED}

Entende-se que a avaliação deve ser realizada pelo professor durante todo o processo e a todos os alunos mediante a observação. Por outra parte, a avaliação é responsabilidade compartilhada entre professor e alunos. Durante todo o curso o professor deve acompanhar o desempenho dos alunos nas atividades e comprovar as conquistas alcançadas e as dificuldades experimentadas durante a execução das tarefas.

No final de cada unidade haverá uma autoavaliação por meio de questionário específico para que o aluno valorize o conhecimento adquirido, o que não foi aprendido e também o que foi eficiente durante o desenvolvimento das atividades. Além da autoavaliação, cada unidade didática está relacionada a um trabalho autônomo e cooperativo. A fim de ilustrar um dos recursos avaliativos falaremos da atividade Equipajes baseada no curta-metragem Equipajes (2006) dirigido pelo diretor Toni Bestard e roteiro de Arturo Ruiz. Está relacionada à unidade didática Estudiar en Barcelona. Ao clicar no link da atividade Equipajes, a página inicial, ilustrada pela Figura 7, apresenta todos os links para seu desenvolvimento: fórum de noticias, Parte 1, Parte 2 e a escrita criativa em grupo (Wiki).

A atividade Vocabulário visa testar os conhecimentos prévios dos alunos, além da incorporação de novo vocabulário por meio de exercícios como associação de palavras com seu significado ou definição. A tarefa Corto Equipajes, da parte1, propõe que o aluno, após assistir o filme, interaja com seus colegas na seção do fórum, escrevendo suas hipóteses sobre o acontecido no curta-metragem apoiado em um quadro de imagens e expressões gramaticais. Ele também comentará o relato de um participante validando ou não as hipóteses de seus colegas. Dessa forma as atividades avaliativas são estimuladas pelo contexto e a cooperação é usada como meio importante para explorar a vivência dos jovens, proporcionando a aprendizagem. 


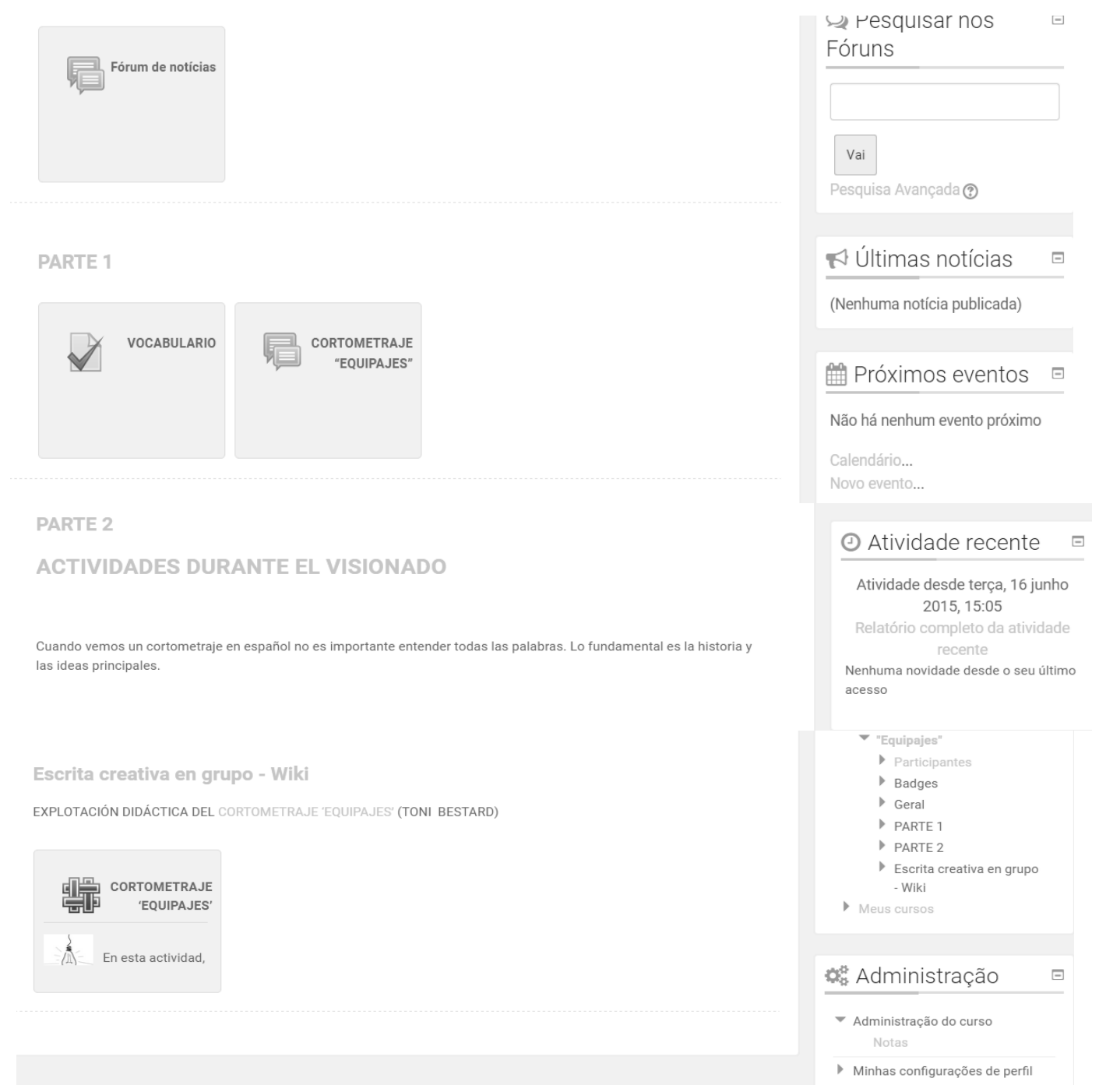

Figura 7. Atividade Equipajes

\section{Discussões e Conclusões}

Através dos cursos de espanhol desenvolvidos no Moodle se repensou a prática educacional mediada pelas TICs, especificamente do idioma espanhol interrelacionando a aprendizagem significativa, a metodologia comunicativa e a abordagem epistemológica dos Cuidados Integrativos.

Quando centramos nosso olhar nos jovens brasileiros que compõem as estatísticas de evasão e abandono escolar, percebe-se que os prejuízos são incalculáveis, traspassam do individual para o familiar e atingem a sociedade como um todo. A tecnologia em si mesma não é capaz de produzir grandes mudanças, é preciso aliá-la a uma metodologia de cuidado cuja estratégia seja integrada e inclusiva. Nesse contexto, o educador-formador deve exercitar a própria imaginação e criatividade com o uso da Web 2.0 na criação de novos materiais e propostas, apostando em uma abordagem de ensino desafiadora repensando seu papel e centrando-se sempre no acolhimento do aluno.

No que tange ao ensino-aprendizagem de idiomas a aquisição de uma língua 
estrangeira nunca esteve tão perto de ser alcançada com o advento da internet e da $\mathrm{Web}$ 2.0. Nesse sentido, diversos estudos têm apontado no Brasil que os educadores ainda não se apropriaram do conhecimento no uso das ferramentas tais como videoconferência, Moodle e outras tecnologias apoiadas em práticas pedagógicas significativas. Sob a égide desse problema, fica então bem clara a importância do diálogo entre os educadores, a comunidade e os setores público e privado, visando criar projetos educacionais alicerçados em bases teóricas e metodológicas eficientes que restitua a todos os brasileiros o direito de aprender, de se profissionalizar, de munir-se com as habilidades e as tecnologias requeridas para o novo milênio.

Uma das maiores preocupações quando se pensa em implantar um projeto promovido pelas TICs, está na incerteza de contar com as instalações adequadas nas escolas públicas dos diversos estados brasileiros. Dentro dessa perspectiva, pretendemos realizar um piloto do Projeto PEINED de maneira a construir um quadro completo que envolva a tabulação de dados referentes à gestão dos recursos necessários e permita refletir de que maneira um determinado grupo de estudantes em uma determinada situação social-educacional, vivencia um momento de inovação tecnológica sob a ótica dos Cuidados Integrativos e uma aprendizagem significativa para a vida toda, acreditando que é possível educar respeitando o ser humano, incluindo seu conhecimento e contexto.

\section{Referências}

Bestard, T. (2006) "Equipajes", The Legal Company Abogados S.L., Espanha, https://youtu.be/VgON3M3PAVM, Setembro.

Bestard, T. (2006) "Equipajes", The Legal Company Abogados S.L., Espanha, https://youtu.be/VgON3M3PAVM, Setembro.

Fontes, S. V. (2014) "Cuidados integrativos", Universidade Federal de São Paulo, http://www.cuidadosintegrativos.com.br/quem-somos?limitstart=0, Outubro.

Littlewood, W. T. (1998), Foreign and second language learning, Cambridge: Cambridge University Press.

Primo, A. (2007), Interação mediada por computador: Comunicação, Cibercultura, Cognição, Sulina.

UNICEF Fundo das Nações Unidas para a Infância no Brasil. (2013) "UNICEF e Campanha Nacional pelo Direito à Educação lançam relatório sobre as crianças e os adolescentes fora da escola e em risco de evasão no Brasil”, UNICEF, Brasil, http://www.unicef.org/brazil/pt/media_24119.htm, Abril. 